\title{
APLIKASI ANALISIS SWOT KUANTITATIF UNTUK FORMULASI STRATEGI PENGEMBANGAN PARIWISATA PERDESAAN DI KAWASAN LERENG MERAPI, DAERAH ISTIMEWA YOGYAKARTA
}

\author{
Joni Purwohandoyo \\ Staf Pengajar Departemen Geografi Pembangunan, Fakultas Geografi UGM. \\ Email : jonipurwo@ugm.ac.id ; joni_4778@yahoo.com
}

Bobby Tumpal Lubis

Staf Ahli Dinas Pekerjaan Umum DIY, Sub Dinas Cipta Karya. Email : bo_loebis@yahoo.com

\section{Okta Fajar Saputra}

Mahasiswa S2 Program Studi Geografi, Fakultas Geografi UGM. Email : okta_fajar@mail.ugm.ac.id

\begin{abstract}
The southern Merapi mountain slope is one of strategic area in Yogyakarta Special Region. This area has many various opportunities, which tourism villages are dispersed on it. This research aim to study the strategic development of tourism villages on southern Merapi mountain slope which use the quantitative SWOT method. There are 12 (twelve) tourism villages in $1^{\text {st }}$ quadrant, 1 (one) tourism village in $2^{\text {nd }}$ quadrant, 2 (two) tourism villages in the $4^{\text {th }}$ quadrant and no one in the $3^{\text {rd }}$ quadrant at the SWOT diagram. The strengthening of internal potent (attractions, accessibilities, infrastructures and management) and reinforcing external opportunities (marketing, investment networking and reducing disaster risk) are primary strategies to promote the development increasing of that tourism villages. For the tourism villages at the $2^{\text {nd }}$ and $4^{\text {th }}$ quadrant (Pancoh, Dukuh, Garongan), internal and also external aspects have to be strengthened. They need seriously and sustainability efforts to develop it.
\end{abstract}

Keywords :

Merapi Mountain Slope Area, Tourism Village, SWOT, Development Strategies

\section{Intisari}

Kawasan lereng Merapi bagian selatan merupakan salah satu kawasan strategis di DIY. Kawasan ini memiliki potensi yang cukup beragam, salah satunya adalah desa-desa wisata yang tersebar di kawasan ini. Penelitian ini bertujuan untuk mengkaji strategi pengembangan desa-desa wisata dengan menggunakan metode SWOT kuantitatif. Terdapat 12 (dua belas) desa 
wisata yang berada pada kuadran I, 1 (satu) desa wisata pada kuadran II, 2 (dua) desa wisata di kuadran IV dan tidak ada yang berada di kuadran III. Strategi penguatan potensi internal (daya tarik, aksesibilitas, infrastruktur, pengelolaan) dan peningkatan kapasitas eksternal (pemasaran, jejaring investasi dan pengurangan resiko bencana) merupakan strategi pokok untuk mendorong peningkatan perkembangan desa-desa wisata tersebut. Untuk desa wisata pada kuadran II dan IV (Pancoh, Dukuh, Garongan), aspek internal dan eksternal perlu semakin intensif untuk diperkuat. Diperlukan upaya yang serius dan berkelanjutan untuk pengembangan ketiga desa wisata tersebut.

Kata Kunci :

Kawasan Lereng Merapi, Desa Wisata, SWOT, Strategi Pengembangan

\section{PENDAHULUAN}

Pariwisata merupakan salah satu sektor yang telah mengambil peranan penting dalam pembangunan perekonomian bangsa-bangsa di dunia. Sektor pariwisata didefinisikan sebagai suatu industri yang berasosiasi dengan menikmati waktu senggang (leisure) dan perjalanan (travel) (Cunha, 2005). Dalam beberapa dekade terakhir, sektor pariwisata telah berkembang sebagai salah satu sektor utama dan tercepat pertumbuhannya yang memberikan kontribusi signifikan terhadap pertumbuhan ekonomi negara-negara di dunia dan juga bagi komunitas lokal masyarakat (Osman \& Sentosa, 2013).

Peran dan kontribusi yang signifikan tersebut telah menjadikan sektor pariwisata sebagai sektor strategis yang perlu ditangani secara serius dan professional. Bagi Indonesia, sektor pariwisata telah memberikan kontribusi yang sangat berarti baik dalam meningkatkan penerimaan devisa, meningkatkan lapangan kerja, menciptakan dampak ekonomi khususnya di sektor UMKM hingga kontribusi dalam konteks pelestarian dan pengelolaan lingkungan, sumber daya alam dan budaya. Prospek dan perkembangan pariwisata akhirakhir ini semakin dinamis dan diikuti dengan perkembangan dari sisi pasar khususnya terkait dengan perubahan pola perjalanan, motivasi, pilihan produk serta tuntutan pelayanan dalam bisnis industri kepariwisataan.

Dalam beberapa dekade terakhir, pengalaman berwisata telah jauh berkembang dimana wisatawan mulai mencari tempattempat untuk dapat berelaksasi dan melepaskan ketegangan (Lin \& Yeh, 2013). Faktor ini berimbas terhadap semakin meningkatnya perhatian terhadap pariwisata perdesaan baik oleh pemerintah, LSM dan para pelaku industri pariwisata. Hal tersebut disebabkan karena pariwisata perdesaan memiliki peran penting sebagai leading economy activity serta mampu membantu meningkatkan pendapatan masyarakat (Egbali, et.al., 2011).

Sebagai salah satu destinasi pariwisata, Daerah lstimewa Yogyakarta menangkap perkembangan dinamika kepariwisataan nasional yang sangat potensial sebagai salah satu aspek dalam peningkatan pendapatan masyarakat. Di kawasan lereng Merapi DIY banyak terdapat desa-desa wisata yang memiliki keunggulan berbeda-beda. Untuk lebih mengoptimalkan potensi desa wisata di lereng merapi tentunya diperlukan strategi pengembangan yang tepat agar dapat berdaya guna dan berhasil guna khususnya bagi masyarakat. Tingginya potensi wisata di desadesa wisata lereng Merapi perlu dukungan agar dapat dikembangkan secara lebih optimal dari berbagai pihak.

\section{TUJUAN}

Tujuan dari tulisan ilmiah ini adalah untuk mengkaji rumusan bentuk strategi pengembangan yang tepat bagi desa-desa wisata di kawasan lereng Merapi DIY dengan metode SWOT kuantitatif. 


\section{TINJAUAN PUSTAKA}

Pariwisata perdesaan pada hakekatnya mengacu pada aktivitas pada suatu tempat di wilayah perdesaan dan pariwisata merupakan salah satu prioritas utama kegiatan tersebut. Bahkan, pariwisata dapat digunakan sebagai salah satu alat penggerak perencanaan di wilayah perdesaan, seperti yang sudah dilakukan di Malaysia (Liu, 2006). Pariwisata memiliki kontribusi penting terhadap peningkatan kesejahteraan masyarakat lokal serta peningkatan pengalaman bagi wisatawan yang berkunjung ke wilayah perdesaan.

Dalam kaitannya dengan promosi destinasi wisata, citra dan strategi yang digunakan untuk target area tertentu seharusnya lebih ditekankan. Hal ini sejalan dengan beberapa penelitian terdahulu yang sebelumnya pernah dilakukan, yaitu menekankan pada pentingnya komponen lingkungan yang ditujukan untuk pengembangan industry pariwisata yang berkelanjutan (Chandralal, 2010; Miller, 2001), serta strategi daya saing destinasi wisata (Kim, 2012). Selain itu, atraksi pusaka dan budaya (seperti industri kerajinan dan amenitas budaya) juga menjadi variabel peubah penting yang berperan dalam industri pariwisata perdesaan serta sebagai pendorong peningkatan pendapatan masyarakat (Rahmani, Hajari, Karimian, \& Hajilo, 2013).

Daya saing pariwisata mengacu pada kemampuan destinasi pariwisata dalam menarik pengunjung untukberkunjungataumengunjungi kembali atau setidaknya untuk mengelola dan meningkatkan posisi pasar antar waktu (d'Hauteserre, 2000). Keunggulan komparatif (sumberdaya alam dan buatan) dan keunggulan kompetitif (infrastruktur pariwisata) digunakan sebagai dasar untuk menjelaskan model daya saing secara keseluruhan (Crouch \& Ritchie, 1999). Daya saing destinasi wisata juga mengacu pada nilai penting praktek-praktek keberlanjutan serta aplikasi upaya-upaya pemasaran destinasi secara benar (Dwyer \& Kim, 2003) dalam rangka meningkatkan daya saing tersebut. Pada gilirannya, suatu destinasi dikatakan meningkat daya saingnya apabila kriteria tertentu dari daya saing destinasi pariwisata tersebut terpenuhi. Sebagai contohnya adalah peningkatan jumlah kunjungan wisatawan dan finansial (Hassan, 2000) serta pertumbuhan kesejahteraan ekonomi penduduk setempat sebagai sumberdaya inti yang semakin kuat (Dwyer \& Kim, 2003; Wilde \& Cox, 2008).

Infrastruktur pariwisata itu sendiri didefinisikan sebagai elemen fisikal yang dibentuk atau dibuat untuk disediakan bagi pengunjung dan memberikan kerangka dasar terhadap efektivitas fungsional sistemsistem pembangunan seperti pada area-area perkotaan, industri dan pariwisata (Inskeep, 1991). Selanjutnya, Chee-Hua, et.al., (2014) membedakan infrastruktur pariwisata ke dalam dua katehgori utama yaitu soft infrastructure (seperti pengembangan bisnis, pelatihan) dan hard infrastructure (seperti fasilitas-fasilitas transportasi, informasi, akses bagi wisatawan). Pada dasarnya, infrastruktur pariwisata terdiri dari keseluruhan tipe infrastruktur transportasi, amenitas wisata serta yang memfasilitasi sumberdaya (Wilde \& Cox, 2008; Khadaroo \& Seetanah, 2008) yang bernilai penting untuk membantu meningkatkan daya saing destinasi pariwisata.

\section{METODE}

Perkembangan metode atau teknik analisis SWOT khususnya yang bersifat kuantitatif telah banyak digunakan oleh para peneliti sebelumnya. Dalam perkembangannya, teknik analisis ini juga dipadukan dengan beberapa jenis teknik analisis kuantitatif lainnya. Ho (2008) bahkan sudah menelusur berbagai jenis penggunaan teknik analisis ini, meskipun dalam tulisan tersebut, SWOT justru hanya sebagai pendukung dari teknik analisis matematikkuantitatif yang sudah baku sebelumnya

\section{\begin{tabular}{l|} 
JNP \\
68
\end{tabular}}


Tabel1. Penggunaan teknik analisis SWOT beserta kombinasinya
No Penulis
Keterangan
$1 \quad$ Kajanus, M., et. al., (2004)
Penggunaan teknik analisis SWOT yang dikombinasikan dengan A'WOT analisis. digunakan untuk menentukan faktor potensi sukses dalam pengembangan pariwisata perdesaan (Yla-Savo di Finlandia dan Kassel di Jerman). A'WOT adalah suatu metode hybrid yang merupakan kombinasi antara SWOT-AHP yang
2 Ho, W., (2008)
Tinjauan literatur penggunaan teknik analisis Analytic Hierarchy Process (AHP) dan kombinasinya dengan teknik-teknik analisis kuantitatif lainnya. Kajian ini difokuskan pada berbagai model penggunaan AHP beserta penerapannya di berbagai bidang penelitian (salah satunya adalah pariwisata). Penggunaan kombinasi teknik analisis ini pernah diaplikasikan oleh Kajanus, et.al., (2004) untuk evaluasi faktor-faktor dalam perencanaan pariwisata perdesaan.
3 Castellani, V., et. al., (2010)
Pengunaan teknik analisis SWOT yang dikombinasikan dengan Sustainable Performance Index (SPI). SWOT digunakan untuk memisahkan variabel berdasarkan aspek kekuatan, kelemahan, peluang dan ancaman dengan mendasarkan pada indikator-indikator sustainable tourism pada suatu destinasi wisata.
4 Fons, M.V.S., et. al., Penggunaan metode analisis SWOT untuk pengkayaan keuntungan dan kerugian (2011) pengembangan Pariwisata Perdesaan, bersifat deskriptif kualitatif.
$5 \quad$ Kajanus, M., et. al., (2012)
-Penggunaan kombinasi metode Multiple Criteria Decision Support (MCDS) dengan metode analisis SWOT untuk menentukan strategi pengelolaan sumberdaya alam (kehutanan) dan
6 Zhang, X., (2012) kebijakan pemanfaatan potensi ekonomi yang dapat dilakukan.
- Analisis SWOT memberikan kerangka dasar untuk analisis operasional lingkungan untuk mendukung pengambilan keputusan.
- Analisis MCDS digunakan sebagai penajaman analisis SWOT untuk menentukan alternatif-alternatif strategi yang dapat diprioritaskan.
Penggunaan analisis SWOT untuk evaluasi pengembangan pariwisata perdesaan di Suzhou. Melalui kombinasi sumberdaya internal dan lingkungan eksternal, dapat ditentukan umpan balik penilaian terhadap kekuatan, kelemahan, peluang dan tantangan dalam pengembangan dan pembangunan pariwisata perdesaan berkelanjutan di Suzhou.
$7 \quad$ Yavuz, F., \& T. Penggunaan teknik analisis SWOT-AHP untuk menentukan strategi pengelolaan Danau Baycan, (2013) Beysehir, Turki. Studi ini menggambarkan kombinasi teknik analisis SWOT-AHP dalam memilah preferensi stakeholder dalam proses pengambilan keputusan.
8 Ghorbani, A., et. al., (2015) Penggunaan teknik analisis SWOT yang dikombinasikan dengan teknik analisis Quantita
Strategic Planning Matrix (QSPM) yang digunakan untuk mengidentifikasi kebutuhan managemen strategis pengembangan destinasi pariwisata berkelanjutan.
9 Gro, P., et. al., (2015) Penggunaan teknik analisis SWOT yang dikombinasikan dengan Analytic Network Process (ANP). Teknik analisis ini merupakan bagian dari 3 (tiga) fase pengambilan keputusan untuk pemecahan masalah lingkungan pada area pegunungan dengan memasukkan indikator kehutanan, pertanian, pariwisata dan perlindungan alam.
9 White, T. H., et. al., (2015) Aplikasi teknik analisis SWOT kuantitatif untuk evaluasi secara obyektif terhadap konservasi spesies dan restorasi ekologis melalui proses translokasi dan reintroduksi spesies. Metode analisis ini juga digunakan untuk pemilihan area atau site serta bagaimana hasil analisis digunakan untuk identifikasi manajemen aksi dan monitoring secara lebih efektif dan efisien. 
Tulisan Kajanus (2004) merupakan salah satu contoh yang paling relevan untuk penerapan teknik analisis ini dalam konteks pariwisata perdesaan. Penelitian ini dilakukan di 15 (lima belas) Desa Wisata yang tersebar di sekitar lereng Gunung Merapi bagian selatan yang menjadi bagian administratif Kabupaten Sleman (DIY). Indikator dan variabel ditentukan berdasarkan aspek penilaian internal (faktor internal) dan eksternal (faktor eksternal). Masing-masing faktor selanjutnya ditentukan nilai bobotnya, dimana total jumlah bobot adalah 1 .
Setiap faktor dapat bernilai sebagai kekuatan (strengths) ataupun kelemahan (weaknesses). Demikian juga untuk indikator dan variabel pada faktor eksternal, dimana masingmasing dapat berkemungkinan sebagai peluang (opportunities) atau bahkan ancaman/tantangan (threats). Masing-masing variabel diberikan skor 1-5 berdasarkan posisinya dalam tabel SWOT. Tabulasi selengkapnya dapat dilihat pada tabel 2 berikut ini.

Tabel 2. Indikator dan Variabel yang Digunakan dalam Penelitian

INDIKATOR

Daya Tarik Wisata

Aksesibilitas

Sarana dan Prasarana

Kelembagaan Pengelolaan

1. Pengelolaan Saat Ini

2. Ketersediaan Struktur Kelembagaan

3. Aspirasi dan Peran Serta Masyarakat

1. Keragaman
BOBOT

0.15

0.15

0.10

0.15

0.05

0.05

0.05

0.05

0.05

0.10

0.05

0.05

1.00

0.25

0.20

0.15

0.05

0.15

0.10

0.10

1.00

TOTAL BOBOT FAKTOR EKSTERNAL

Sumber : Analisis, 2017 
Setlah dilakukan skoring terhadap variabel SWOT, selanjutnya dihitung nilai akhir skor dikalikan bobot untuk tiap variabel dan tiap faktor, yaitu :

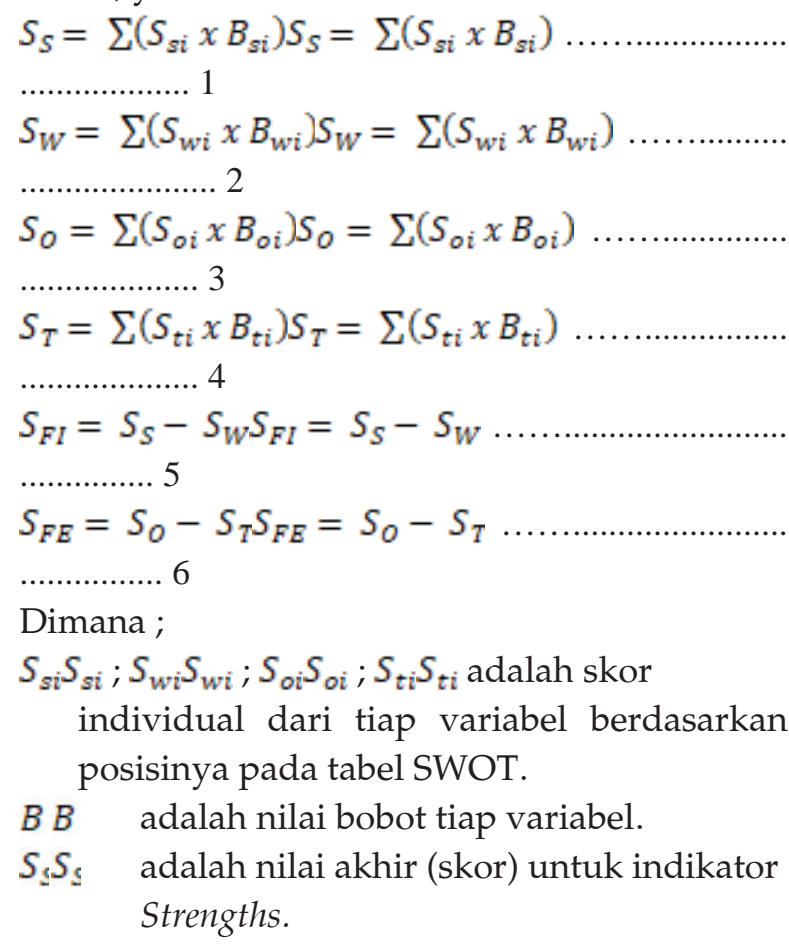

$S_{W} S_{W}$ adalah nilai akhir (skor) untuk indikator Weaknesses.

$S_{O} S_{O} \quad$ adalah nilai akhir (skor) untuk indikator Opportunities.

$S_{T} S_{T}$ adalah nilai akhir (skor) untuk indikator Threats.

$S_{F I} S_{F I}$ adalah nilai akhir (skor) untuk Faktor Internal, sebagai nilai pada sumbu $\mathrm{X}$ dalam kuadran SWOT.

$S_{F E} S_{F E}$ adalah nilai akhir (skor) untuk Faktor Eksternal, sebagai nilai pada sumbu Y dalam kuadran SWOT.

Langkah selanjutnya adalah menyusun hasil perhitungan ke dalam matrik SWOT. Berdasarkan matrik ini, masing-masing desa wisata akan dilihat berada pada kuadran berapa. Dasar penentuan strategi pengembangan adalah posisi masing-masing desa wisata di dalam kuadran SWOT. Perumusan strategi pengembangan desa-desa wisata dapat dilihat pada tabel 3 .

Tabel 3. Formulasi Strategi dengan Menggunakan Matrik SWOT

\begin{tabular}{|c|c|c|}
\hline & Strengths & Weaknesses \\
\hline Opportunities & $\begin{array}{l}\text { - Strategi S-O } \\
\text { - Kuadran I } \\
\text { - Strategi Maxi-Maxi } \\
\text { - Strategi yang ditekankan pada } \\
\text { pemanfaatan KEKUATAN untuk } \\
\text { memaksimalkan PELUANG }\end{array}$ & $\begin{array}{l}\text { - Strategi W-O } \\
\text { - Kuadran II } \\
\text { - Strategi Mini-Maxi } \\
\text { - Strategi yang ditekankan pada upaya } \\
\text { meminimalkan KELEMAHAN untuk } \\
\text { membidik atau mengoptimalkan } \\
\text { PELUANG }\end{array}$ \\
\hline hreats & $\begin{array}{l}\text { - Strategi S-T } \\
\text { - Kuadran III } \\
\text { - Strategi Maxi-Mini } \\
\text { - Strategi yang ditekankan pada } \\
\text { pemanfaatan KEKUATAN untuk } \\
\text { meminimalkan ANCAMAN. }\end{array}$ & $\begin{array}{l}\text { - Strategi W-T } \\
\text { - Kuadran IV } \\
\text { - Strategi Mini-Mini } \\
\text { - Strategi yang ditekankan pada } \\
\text { pengurangan atau minimalisasi } \\
\text { KELEMAHAN internal untuk menghindari } \\
\text { ANCAMAN. }\end{array}$ \\
\hline
\end{tabular}

Sumber : diadopsi dari Yavus and Baycan, 2013 


\section{HASIL DAN PEMBAHASAN}

\subsection{Faktor-Faktor Internal}

Kawasan Lereng Merapi berada di ketinggian antara 100 hingga 1000 mdpal. Kawasan ini beriklim tropis basah dan suhu udara berkisar antara 18-23 derajat Celcius. Dari segi morfologi wilayah, kawasan ini memiliki keragaman morfologis mulai dari dataran hingga lereng terjal berupa igir dan lembahlembah yang dalam. Kondisi alam di sebagian besar lereng Merapi tersebut yang dijadikan sebagai potensi daya tarik wisata utama bagi desa-desa wisata di kawasan tersebut.

Selain pemandangan Gunung Merapi, kebun-kebun salak juga menjadi potensi wisata pendukung bagi kawasan ini. Kebun-kebun salak milik warga banyak dijadikan sebagai daya tarik wisata. Kebun salak juga dapat dijadikan sebagai sarana untuk pembelajaran budidaya dan pengolahan salak, baik berupa buah salak maupun limbah kulit salak.
Kawasan Lereng Merapi juga memiliki kekayaan budaya yang beragam. Kebudayaan dan kesenian yang disuguhkan oleh desadesa wisata di Kawasan Lereng Merapi diantaranya Sadranan, Pagerbumi, Merti Bumi, Bergodo Prajurit, Kenduri, Tari Salak, Jathilan, Klentingan, Karawitan, Phonokawan, Gamelan, Hadroh, dan Kuda Lumping.

Bentuk lain pengembangan desa wisata juga dilakukan dengan mengoptimalkan potensi daya tarik industri atau ekonomi kretaif. Namun dalam perkembangannya, hanya sedikit desa wisata yang mengembangkan wisatanya melalui daya tarik wisata industri dan ekonomi kreatif. Daya tarik wisata lainnya yang dikembangkan oleh desa-desa wisata berupa daya tarik buatan.

Daya tarik wisata berupa kuliner di beberapa desa wisata hampir memiliki kesamaan. Wisata kuliner yang dikembangkan di desa-desa wisata adalah berupa hasil olahan salak. Jenis atraksi ini menyebabkan kuliner-kuliner di beberapa desa wisata juga menjadi khas dan daya tarik tersendiri jika dibandingkan dengan desa wisata lainnya.

Tabel 4. Variasi Atraksi Desa-Desa Wisata di Kawasan Lereng Merapi DIY

Daya Tarik

Alam
Variasi Atraksi

Keindahan alam dan lingkungan
View Gunung Merapi, Sungai
Kebun Salak
Tracking Alam, Ledok/Lembah
Sungai, Tracking Sungai
Goa, Pancuran
Sawah

Desa Wisata

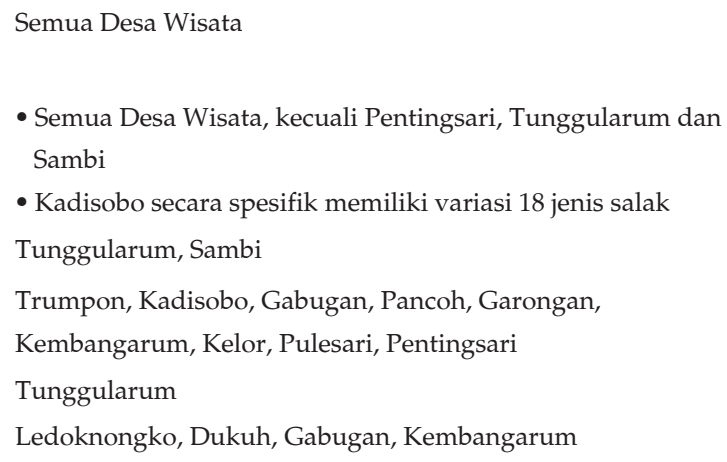


Daya Tarik

Budaya

Buatan

Kuliner
Variasi Atraksi

Desa Wisata

Tari-Tarian (Jathilan, Kuda Lumping, Tari Pulesari, Kelor, Pentingsari, Sambi, Srowolan, Trumpon, Salak, Tari Ramayana, Tari Penyambutan/ Kadisobo, Nganggring

Pekbung, dll), Sanggar Tari

Gamelan dan Karawitan, Campursari,

Laras Madyo, Gejug Lesung, dll.

Even Budaya (Sadranan, Merti Bumi, Pagelaran Wayang, Kethoprak, dll)

Tradisi Budaya (Slametan, Kenduri, Ronda Malam, Wiwitan, dll)

Melukis, Membatik

Situs Batu Keramat/Watu Kotak

Lainnya (Permainan Anak-Anak

Tradisional)

Outbond, Game Air

Flying Fox

Camping Ground

Kolam Pemancingan

Atraksi Perdesaan (Tanam Padi, Bajak

Sawah, Berkebun, Memerah Susu Sapi, dll).

Atraksi Kegunungapian (Volcano Tour, Bunker, Gardu/Menara Pandang,

Jembatan Penahan Lahar)

Resort

Produk Kulit Salak (Tas, Gantungan

Kunci, dll)

Kerajinan Membatik, Wayang Suket,

Kreasi Janur

Pengolahan Sampah Plastik

Pelatihan (Pupuk Organik, Budidaya dan Pengolahan Salak)

Makanan Berbahan Dasar Salak (Sambal, Oseng, Nasi Pondoh, Wajik, Keripik, Bakpia, Dodol, Karamel, Koktail, Selai, Keripik, dll)

Makanan Tradisional (Gatot, Tiwul, Keripik Pegagan, Sego Megono, Tempe Bacem)

Minuman Tradisional (Jahe, Sere)
Pulesari, Pentingsari, Tunggularum, Sambi, Srowolan, Kadisobo, Dukuh, Gabugan, Nganggring, Pancoh,

Garongan

Pulesari, Tunggularum, Sambi, Ledoknongko, Dukuh, Nganggring, Pancoh

Pentingsari, Tunggularum, Sambi, Srowolan, Trumpon, Gabugan, Nganggring, Pancoh

Gabugan, Kembangarum

Kadisobo

Kembangarum

Semua Desa Wisata kecuali Tunggularum, Trumpon, Ledoknongko, Dukuh

Kelor

Pancoh, Garongan, Kembangarum

Pentingsari, Srowolan, Kadisobo, Gabugan, Garongan

Pentingsari, Sambi, Dukuh, Gabugan, Nganggring

(Kambing PE), Pancoh

Pentingsari, Tunggularum, Sambi, Trumpon, Pancoh

Sambi

Kelor, Kadisobo

Pentingsari

Srowolan

Kadisobo, Ledoknongko

Pulesari, Kelor, Srowolan, Trumpon, Kadisobo, Gabugan, Kembangarum

Gabugan, Tunggularum, Kelor

Pulesari

Sumber : Survei Lapangan (2015) dan Analisis (2015, 
Dilihat dari aspek keragaman daya tarik tersebut maka dapat dikatakan bahwa setiap desa wisata di Kawasan Lereng Merapi memiliki keragaman yang bervariasi. Rata-rata setiap desa wisata memiliki daya tarik lebih dari 3 (tiga) jenis. Berbagai daya tarik tersebut juga sudah diintegrasikan satu dan yang lainnya oleh pengelola. Namun jika dilihat dari aspek keunikan, justru setiap desa wisata tidak memiliki keunikan desanya masing-masing. Hal tersebut karena atraksi yang ditawarkan oleh desa wisata yang satu cenderung hampir sama dengan atraksi yang ditawarkan oleh desa wisata lainnya.

Selain atraksi wisata, aspek internal lainnya yang cukup berpengaruh terhadap perkembangan desa wisata adalah aksesibilitas. Secara regional, jalur masuk menuju Kawasan Lereng Merapi dari arah luar kota dapat dicapai dari jalur Jalan Magelang. Jalur ini menampung pengunjung dari arah Semarang, Magelang dan sekitarnya. Sedangkan dari arah timur (Solo dan sekitarnya) pengunjung akan melewati simpul utama wilayah pinggiran Kota Yogyakarta dan atau Kota Yogyakarta itu sendiri. Baru kemudian dapat terdistribusi secara merata melalui tiga jalur utama yaitu Jalan Kaliurang, Jalan Palagan dan Jalan Magelang.

Koridor utama di dalam Kawasan Lereng Merapi (selain jalan masuk utama) terdapat 2 (dua) koridor melintang arah timur-barat. Koridor pertama adalah yang melintasi kota Kecamatan Pakem menuju ke barat sampai dengan Jalan Magelang. Jalur ini terletak di bagian tengah dan merupakan koridor yang strategis yang dapat dicapai untuk menuju ke berbagai arah di Kawasan Lereng Merapi. Sedangkan koridor kedua adalah koridor dari arah Tempel menuju kerah timur dan utara di bagian atas. Koridor ini melintasi bagian utara Kabupaten Sleman.

Dilihat dari aksesibilitasnya, sebagian besar desa wisata di Kawasan Lereng Merapi sudah dihubungkan dengan jalan yang memadai. Akses jalan menuju lokasi desa wisata umumnya dihubungkan dengan jalan kolektor ataupun jalan lokal dengan kualitas baik dan lebar. Desadesa wisata di Kawasan Lereng Merapi dapat dijangkau dengan bus ukuran sedang hingga besar. Sedangkan dari aspek aksesibilitas internal, jalan yang ada di dalam lokasi desa wisata rata-rata kondisinya baik.

Permasalahan terkait aksesibilitas desa wisata adalah belum tersedianya akses angkutan umum dari Kota Yogyakarta menuju lokasi desa wisata. Ketidaktersediaan angkutan umum tersebut terjadi di semua desa wisata. Desa-desa wisata hanya dapat diakses oleh kendaraan pribadi ataupun agen perjalanan untuk mengantarkan wisatawan. Hal tersebut menjadi masalah jika wisatawan yang akan datang menuju lokasi desa wisata merupakan wisatawan dalam kelompok kecil.

Dari segi pengelolaan desa wisata, umumnya dilakukan oleh masyarakat setempat. Pengelola desa wisata bisa berupa perwakilanperwakilan masyarakat yang ditunjuk ataupun kelompok yang sebelumnya sudah ada di masyarakat yang merangkap menjadi pengelola. Kelompok yang sebelumnya sudah ada tersebut bisa berupa kelompok tani, kelompok ternak, ataupun karang taruna. Pengelola desa wisata di Kawaasan Lereng Merapi belum ada satupun yang berbadan hukum.

Di desa wisata yang sudah terstruktur kelembagaannya, masing-masing kelompok memiliki peran masing-masing dalam upaya pengembangan desa wisata. Seperti di Desa Wisata Kadisobo, masing-masing kelompok masyarakat diberi peran dalam kegiatan wisata. UPPKS berperan bagi pengembangan wisata kuliner dan pengolahan salak, Lohjinawi berperan sebagai pengelola sampah dan pertanian organik, kelompok perikanan berperan sebagai pemasok kebutuhan daya tarik wisata pemancingan dan rumah makan, serta komunitas Hobi Burung berperan sebagai pengembang daya tarik wisata musiman berupa kontes burung. 
Permasalahan lain yang biasanya dihadapi oleh kelompok pengelola adalah, keterampilan dan sumberdaya manusia. Hanya sebagian dari anggota kelompok yang mengerti dengan sistem pengelolaan wisata. Bahkan tidak sedikit yang sistem pengelolaan wisatanya tidak terstruktur dengan baik. Oleh karena itu sebenarnya masih diperlukan proses pembinaan dan pelatihan kepada masyarakat kelompok pengelola secara lebih intensif.

\section{Faktor-Faktor Eksternal}

Aspek eksternal yang menjadi fokus analisis dalam kajian ini adalah aspek pasar, investasi dan dampak terhadap lingkungan. Aspek-aspek tersebut dipertimbangkan sebagai faktor eksternal dengan pertimbangan bahwa ketiganya merupakan faktor yang bersifat 'dari' atau 'ke' luar. Selain itu aspek-aspek tersebut dapat terjadi oleh karena adanya suatu input atau kejadian yang terlebih dahulu ada sebelumnya. Sehingga ketiganya menjadi faktor peubah yang tidak serta merta dapat langsung ditentukan nilainya apabila ada pengaruh dari aspek-aspek yang sudah ada (internal) di dalam desa-desa wisata itu sendiri.

Dari segi pasar wisatawan, jangkauan pasar terhadap desa wisata di Kawasan Lereng Merapi saat ini sudah cukup luas. Tidak hanya pasar lokal di tingkat kota atupun provinsi, melainkan juga skala nasional bahkan hingga internasional. Namun terjadi kesenjangan antara desa wisata yang satu dengan desa wisata yang lain dalam hal intensitas dan frekuensi kunjungan wisatawan. Desa-desa wisata seperti Pentingsari, Pulesari, Kelor dan beberapa desa lainnya memiliki pasar yang luas hingga mancanegara dengan intensitas kunjungan yang cukup besar.

Berdasarkan kondisi di atas, terlihat bahwa arah pengembangan desa wisata saat ini masih berorientasi pada pengembangan desa wisata untuk kunjungan massal. Utamanya adalah untuk kegiatan kunjungan anak sekolah.
Hal tersebut yang menyebabkan intensitas kunjungan wisatawan juga menjadi tidak menentu. Kunjungan akan sangat banyak di hari-hari libur, dan akan sangat sepi di hari-hari sekolah.

Dari segi investasi, kebanyakan desa-desa wisata di kawasan lereng Merapi sudah cukup mandiri dengan mengandalkan keterlibatan investasi dari warga masyarakat sendiri. Kegiatan pariwisata di desa wisata umumnya belum mampu menarik investasi dari luar. Bentuk investasi swasta yang masuk di desa wisatapun umumnya hanya berupa arena outbond ataupun resort dan penginapan.

Investasi pembangunan arena outbond dan penginapan yang banyak dilakukan, umumnya justru tidak berdampak langsung bagi perekonomian masyarakat. Karena arena outbond dan penginapan memiliki sistem pengelolaan sendiri yang tertutup aksesnya bagi masyarakat. Selain investasi oleh swasta, di beberapa desa wisata juga mengandalkan investasi pemerintah, melalui dana PNPM. Seperti yang dilaukan di Desa Wisata Garongan, Trumpon, Pulesari, Tunggularum, dan Kelor.

Sedangkan bentuk-bentuk investasi yang banyak dilakukan oleh masyarakat berupa investasi sederhana. Sistem yang digunakan adalah sewa aset pribadi oleh pengelola desa wisata atau ada pula sistem bagi hasil di akhir kegiatan pariwisata, antara pemilik aset dengan pengelola.

Selain aset pribadi, ada pula beberapa aset yang dimiliki bersama, biasanya dalam bentuk swadaya pembangunan oleh masyarakat ataupun penggunaan dana kas desa. Sistem yang digunakan dalam pemanfaatan aset bersama adalah dengan cara membagi hasil. Selain itu, dampak kegiatan pariwisata terhadap perekonomian masyarakat juga cukup terasa. Ketika ada kunjungan wisatawan, secara langsung perputaran ekonomi di desa tersebut juga akan bergerak.

Aspek eksternal lainnya yang dapat menjadi ancaman bagi desa-desa wisata adalah 
kerawanan terhadap resiko bencana Gunungapi Merapi. Ancaman kebencanaan di Kawasan Lereng Merapi adalah letusan Gunungapi Merapi. Ancaman bahaya letusan gunungapi tersebut bisa berupa bahaya primer ataupun sekunder. Berbagai bahaya yang termasuk dalam bahaya letusan primer diantaranya bahaya awan panas, lontaran material pijar, hujan abu lebat, aliran lava, dan gas beracun. Sedangkan bahaya yang termasuk dalam bahaya sekunder adalah material hasil letusan gunung api yang terbawa oleh aliran air hujan, bisa berupa lahar, lumpur, dan banjir bebatuan.

Badan Nasional Penanggulangan Bencana (BNPB) telah membuat peta kerawanan bencana letusan Gunungapi Merapi. Berdasarkan peta kerawanan bencana tersebut, diketahui bahwa sebagian besar desa wisata di kawasan Lereng Merapi masuk dalam lokasi yang relatif aman dari bahaya letusan Gunung Merapi. Hanya beberapa desa yang masuk dalam zona rawan bencana. Desa-desa yang memiliki potensi terdampak letusan Gunung Merapi yaitu :

- Tunggularum : Area terdampak letusan tahun 2010, Zona KRB II

- Nganggring : Zona KRB II

- Pentingsari : Zona KRB II

- Sambi : Zona KRB I

Desa wisata Tunggularum, Ngangring, dan Pentingsari berada di zona rawan bencana II, yaitu berpotensi terkena aliran awan panas, gas beracun, guguran batu pijar, aliran lahar, lontaran batu pijar dan hujan abu lebat ketika letusan terjadi. Hal tersebut dikarenakan letak kedua desa wisata tersebut yang sangat dekat dengan puncak Merapi, yaitu kurang dari $2 \mathrm{Km}$. Sedangkan Desa Wisata Sambi selain masuk dalam Kawsan Rawan Bencana I, lokasinya yang berada di bantaran Kali Kuning juga memiliki potensi terdampak bahaya lahar/banjir lahar dan perluasan awan panas.

\subsection{Analisis SWOT Kuantitatif dan Formulasi Strategi Pengembanagn Desa Wisata}

Penilaian dngan teknik SWOT kuantitatif bersifat relatif berdasarkan hasil pengamatan lapangan, Focus Group Discussion (FGD) serta informasi-informasi pendukung dari informan terkait. Meskipun bersifat relatif, penilaian dilakukan secara obyektif untuk menjamin obyektivitas hasil penilaian.

Dari aspek internal, terdapat 5 (lima) desa wisata yang memiliki kekuatan (strengths) tertinggi. Sedangkan desa-desa wisata yang memiliki nilai kelemahan (weaknesses) tertinggi adalah Desa Wisata Dukuh, Garongan dan Pancoh.

Dari aspek eksternal, desa-desa wisata dengan nilai peluang atau keuntungan (opportunities) tertinggi juga terdapat 5 (lima) desa wisata. Sedangkan desa-desa wisata dengan ancaman (threats) tertinggi adalah Desa Wisata Dukuh dan Garongan. Hasil selengkapnya dapat dilihat pada tabel berikut :

Tabel 5. Hasil Perhitungan SWOT Kuantitatif

\begin{tabular}{|c|c|c|c|c|c|c|c|}
\hline & DESA & & $\begin{array}{l}\text { TR FA } \\
\text { [ERN }\end{array}$ & $\begin{array}{l}\text { TOR } \\
\text { L (X) }\end{array}$ & $\begin{array}{l}\text { SK } \\
\text { EK }\end{array}$ & $\begin{array}{l}\text { R FAl } \\
\text { TERN }\end{array}$ & $\begin{array}{l}\text { KTOR } \\
\text { AL (Y) }\end{array}$ \\
\hline & & $\mathrm{S}$ & $\mathbf{W}$ & S-W & $\mathrm{O}$ & $\mathbf{T}$ & O-T \\
\hline 1 & Dukuh & 0.90 & 1.65 & -0.75 & 1.10 & 2.85 & -1.75 \\
\hline 2 & Gabugan & 1.65 & 0.65 & 1.00 & 2.55 & 0.30 & 2.25 \\
\hline 3 & Garongan & 1.50 & 1.65 & -0.15 & 1.00 & 2.65 & -1.65 \\
\hline 4 & Kadisobo & 2.60 & 0.30 & 2.30 & 2.50 & 1.05 & 1.45 \\
\hline 5 & Kelor & 3.85 & 0.15 & 3.70 & 3.30 & 0.30 & 3.00 \\
\hline 6 & Kembangarum & 3.30 & 0.65 & 2.65 & 3.50 & 1.15 & 2.35 \\
\hline 7 & Ledoknongko & 1.80 & 0.95 & 0.85 & 1.60 & 1.35 & 0.25 \\
\hline 8 & Nganggring & 2.75 & 0.30 & 2.45 & 2.15 & 0.90 & 1.25 \\
\hline 9 & Pancoh & 1.55 & 1.00 & 0.55 & 1.20 & 1.60 & -0.40 \\
\hline 10 & Pentingsari & 3.95 & 0.15 & 3.80 & 3.95 & 0.30 & 3.65 \\
\hline 11 & Pulesari & 3.80 & 0.15 & 3.65 & 3.95 & 0.10 & 3.85 \\
\hline 12 & Sambi & 3.85 & 0.15 & 3.70 & 3.25 & 1.15 & 2.10 \\
\hline 13 & Srowolan & 2.85 & 0.65 & 2.20 & 2.45 & 0.90 & 1.55 \\
\hline 14 & Trumpon & 2.25 & 0.25 & 2.00 & 2.15 & 0.35 & 1.80 \\
\hline 15 & Tunggularum & 2.00 & 0.95 & 1.05 & 1.30 & 1.10 & 0.20 \\
\hline
\end{tabular}




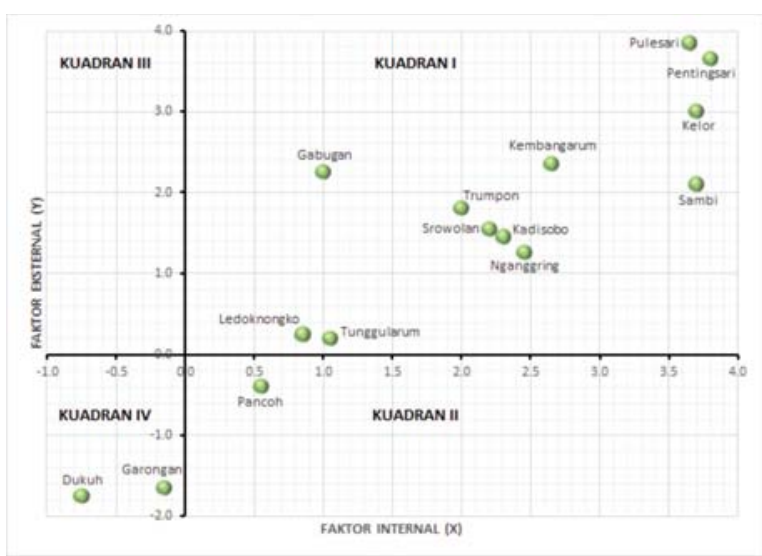

Gambar 1. Hasil Plotting Desa-Desa Wisata dalam Kuadran SWOT

Berdasarkan gambar 1 di atas terlihat bahwa sebagian besar desa wisata di kawasan Lereng Merapi berada pada kuadran I. Artinya bahwa sebagian besar desa wisata tersebut memiliki kekuatan yang lebih besar dan juga peluang pengembangan yang juga lebih besar. Meskipun demikian, apabila diamati secara lebih spesifik, terdapat beberapa desa wisata yang posisinya relatif masih minim. Khususnya jika dilihat dari aspek peluang eksternal. Desa wisata tersebut adalah Desa Wisata Ledoknongko dan Tunggularum.

Terdapat pula beberapa desa wisata pada kuadran I yang posisinya sudah cukup kuat akan tetapi masih relatif medium. Desa wisata tersebut meliputi Desa Wisata Trumpon, Srowolan, Kadisobo dan Nganggring. Desa Wisata Kembangarum memiliki tingkat kekuatan internal yang sama dengan keempat kelompok desa wisata tersebut, akan tetapi peluang eksternalnya lebih besar. Sehingga posisinya relatif masih cenderung lebih kuat dari keempat desa wisata tersebut.

Salah satu desa wisata pada kuadran I dengan karakter yang berbeda adalah Desa Wisata Gabugan. Desa wisata ini secara potensi internal memiliki kekuatan yang sama dengan Desa Tunggularum. Akan tetapi peluang eksternalnya jauh lebih besar daripada Desa Wisata Tunggularum. Sehingga posisinya juga relatif lebih kuat daripada Desa Wisata tunggularum.

Sementara itu terdapat kelompok desa wisata yang memiliki posisi paling kuat. Desa wisata tersebut ada 4 (empat) yaitu Desa Wisata Pulesari, Pentingsari, Kelor dan Sambi. Keempatnya memiliki kekuatan internal yang hampir sama. Faktor pembedanya adalah pada kekuatan eksternal. Posisi kawasan terhadap kerawanan bencana Gunung Merapi menjadi faktor yang membedakan posisi dari keempat desa wisata tersebut.

Secara umun, faktor internal yang menjadi penguat dari desa-desa wisata di kuadran I adalah faktor keunikan dan keragaman daya tarik wisata. Selain itu juga dukungan aksesibilitas dan kelengkapan infrastruktur menjadi faktor penting bagi perkembangan desa-desa wisata pada kuadran tersebut. Sedangkan dari aspek eksternal, jumlah kunjungan dan jangkauan pemasaran menjadi faktor paling dominan. Sedangkan faktor yang melemahkan dari aspek eksternal umumnya adalah aspek kebencanaan.

Pada kuadran II, hanya terdapat satu desa wisata yaitu Desa Wisata Pancoh. Desa wisata ini memiliki potensi atau kekuatan internal yang sudah cukup baik, akan tetapi faktor eksternalnya masih dalam posisi negatif. Jumlah kunjungan wisatawan, investasi dan kerawanan bencana yang cukup besar menjadi faktor-faktor yang melemahkan dari aspek eksternal.

Sedangkan pada kuadran IV, terdapat 2 (dua) desa wisata yaitu Desa Wisata Dukuh dan Garongan. Kedua desa wisata tersebut memiliki kekuatan internal yang negatif dan peluang eksternal yang juga kurang menguntungkan. Sehingga kedua desa wisata ini relatif tidak berkembang atau sulit untuk meningkatkan perkembangan keduanya. Diperlukan suatu upaya yang cukup serius apabila akan mendorong kedua desa wisata tersebut untuk bergeser kearah yang positif.

Dalam konteks formulasi strategi pengembangan desa wisata, untuk kuadran I relatif lebih mudah untuk menodorong 
perkembangan desa-desa wisata tersebut. Pada kuadran I diperlukan strategi yang sifatnya "Maxi-Maxi", yaitu strategi pengembangan yang mengedepankan pengembangan potensi (memaksimalkan potensi) yang dimiliki untuk memperoleh peluang yang semakin besar atau semakin meningkat. Strategi tersebut dapat berupa ; (1) peningkatan kualitas dan keragaman atraksi wisata, (2) peningkatan kualitas aksesibilitas dan penyediaan infrastruktur, (3) peningkatan jaringan pemasaran, dan (4) peningkatan penanganan terhadap resiko bencana. Meskipun demikian, secara spesifik, strategi pendukung untuk setiap desa wisata akan berbeda antara satu desa dengan desa wisata lainnya.

Formulasi strategi untuk kuadran II, ditekankan pada konteks "Maxi-Mini" khususnya untuk Desa Wisata Pancoh. Strategi umum untuk desa wisata tersebut utamanya adalah memaksimalkan potensi untuk meminimalkan ancaman. Potensi wisata yang sudah dimiliki, semakin ditingkatkan kualitasnya. Hal ini juga perlu didukung dengan perluasan jangkauan dan jaringan pemasaran untuk meningkatkan peluang. Dari aspek ancaman, perlu ditingkatkan aspek penanganan terhadap resiko bencana. Secara spesifik, strategi pengembangan untuk Desa Wisata Pancoh yaitu:

- Peningkatan kualitas aksesibilitas eksternal dan internal, penyediaan sarana transportasi dan peningkatan kemudahan pencapaian.

- Peningkatan kelengkapan dan kualitas infrastruktur penunjang

- Penguatan kelembagaan, profesionalisme pengelolaan dan peningkatan pelibatan atau peranserta masyarakat

- Peningkatan promosi untuk memperluas jangkauan pemasaran dan meningkatkan jumlah kunjungan wisatawan

- Perluasan jejaring pemasaran dengan melibatkan stakeholder eksternal

- Peningkatan kesiapsiagaan terhadap resiko bencana letusan Gunung Merapi.
Sedangkan untuk desa-desa wisata pada kuadran IV (Dukuh dan Garongan) merupakan desa-desa wisata dalam kondisi yang paling minim. Banyak hal yang mesti dibenahi dari kedua desa wisata tersebut. Strategi utamanya adalah "Mini-Mini" yaitu meminimalkan masalah untuk mengurangi ancaman. Persoalan dari aspek internal yaitu kualitas daya tarik, aksesibilitas dan pengelolaan desa wisata perlu diminimalisir. Utamanya adalah meningkatkan potensi internal. Sedangkan dari aspek eksternal perlu diminimalkan permasalahan pemasaran dan investasi. Perlu didorong pengembangan potensi untuk meningkatkan jaringan pemasaran. Disamping itu juga perlu upaya untuk meningkatkan daya tarik investasi bagi kedua desa wisata tersebut untuk mendorong peningkatan peluang pengembangannya. Secara spesifik, strategi pengembangan untuk kedua desa wisata tersebut yaitu :

- Penciptaan atau peningkatan daya kreasi untuk meningkatkan kualitas, keragaman dan pengembangan potensi daya tarik wisata.

- Peningkatan kualitas aksesibilitas internal, penyediaan sarana transportasi dan peningkatan kemudahan pencapaian.

- Peningkatan kelengkapan dan kualitas infrastruktur penunjang

- Penguatan kelembagaan, profesionalisme pengelolaan dan peningkatan pelibatan atau peranserta masyarakat.

- Peningkatan promosi untuk memperluas jangkauan pemasaran dan meningkatkan jumlah kunjungan wisatawan.

- Perluasan jejaring pemasaran dengan melibatkan stakeholder eksternal.

- Perluasan jejaring investasi untuk meningkatkan input pengembangan desa wisata.

- Perluasan dan peningkatan nilai sharing investasi untuk mendorong minat investasi pada desa wisata. 


\section{KESIMPULAN}

Desa-desa wisata di Kawasan Lereng Merapi DIY secara umum memiliki potensi internal yang kuat. Hal ini terbukti dengan 12 (dua belas) desa wisata yang berada pada kuadran I dalam diagram SWOT. Hanya 1 (satu) desa wisata yang berada di kuadran II, 2 (dua) desa wisata di kuadran IV dan tidak ada yang berada di kuadran III. Strategi penguatan potensi (daya tarik, aksesibilitas, infrastruktur, pengelolaan) merupakan strategi pokok yang perlu semakin didorong untuk pola pengembangan pada desadesa wisata di kuadran I. Sedangkan dari aspek eksternal perlu semakin ditingkatkan intensitas dan kualitas pemasaran, jejaring investasi dan pengurangan resiko bencana. Untuk desa wisata pada kuadran II dan IV, aspek internal semakin intensif untuk diperkuat disertai dengan aspek eksternal yang juga semakin ditingkatkan.

\section{UCAPAN TERIMA KASIH}

Tim penulis mengucapkan terima kasih yang sebesar-besarnya kepada Dinas Pariwisata DIY yang telah memfasilitasi kegiatan "Penyusunan Masterplan dan DED Tahap I Desa Wisata Kawasan Lereng Merapi" pada tahun anggaran 2015. Karya ilmiah ini menggunakan sebagian kecil dari data pada kegiatan tersebut yang ditulis kembali dalam konteks, tema dan metode yang berbeda dari kegiatan sebelumnya. Dalam hal ini tim penulis juga menjadi bagian penting dari pelaksanaan dan penyusunan laporan kegiatan yang diselenggarakan oleh Dinas Pariwisata DIY tersebut.

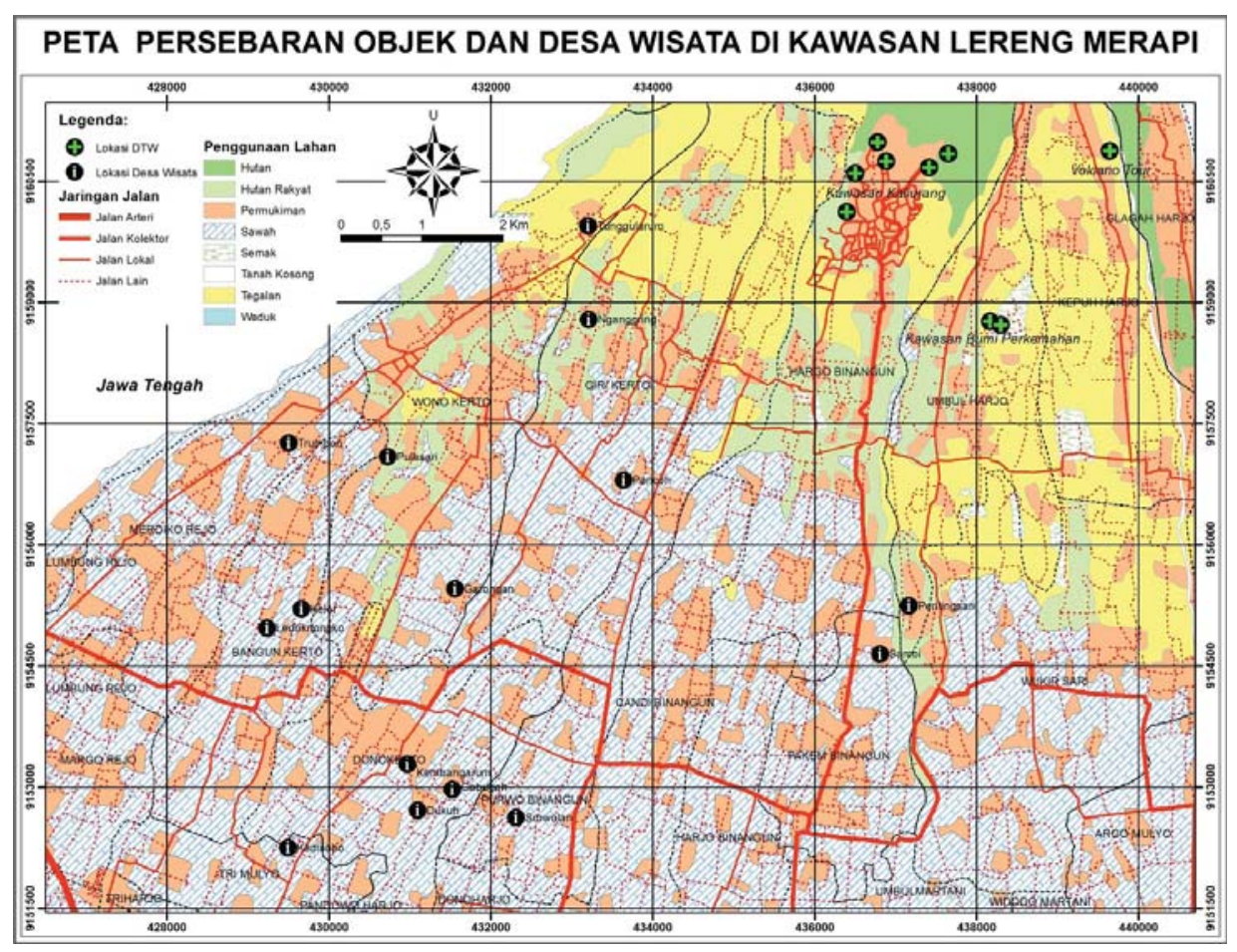

Gambar 2. Peta Sebaran Obyek dan Desa Wisata di Kawasan Lereng Merapi DIY 


\section{DAFTAR PUSTAKA}

Castellani, V., \& Sala, S. (2010). Sustainable performance index for tourism policy development. Tourism Management, 31(6), 871-880. https://doi.org/10.1016/j. tourman.2009.10.001

Chandralal, K. P. (2010). Impacts of Tourism and Community Attitude towards Tourism: A Case Study in Sri Lanka. South Asian Journal of Tourism and Heritage, 3(2), 41-49.

Chee-Hua, Chin. May-Chiun, Lo. Peter Songan. Vikneswaran Nair. (2014). Rural tourism destination competitiveness: A study on Annah Rais Longhouse Homestay, Sarawak. 5th Asia Euro Conference 2014. Procedia - Social and Behavioral Sciences, Vol. 144 (2014) 35 - 44. https://doi: 10.1016/j. sbspro. 2014.07.271.

Crouch, G. I. \& Ritchie, J. R. B. (1999). Tourism, Competitiveness and Societal Prosperity. Journal of Business Research, 44(3), 137-152.

Cunha, S. K. \& Cunha, J. C. (2005). Tourism cluster competitiveness and sustainability: Proposal for a systematic model to measure the impact of tourism on local development. Brazillian Administrative Review, 2(2), 47-62.

d'Hauteserre, A. M. (2000). Lessons in managed destination competitiveness: the case of Foxwoods Casino Resort. Tourism Management, 21(1), 23-32.

Dwyer, L. \& Kim, C. (2003). Destination competitiveness : Determinants and Indicators. Current Issues in Tourism, 6(5), 369-414.

Egbali, N., Nosrat, A. B., \& Alipour, S. K. S. (2011). Effects of positive and negative rural tourism (Case study: Rural Semnan Province). Journal of Geography and Regional Planning, 4(2), 63-76.

Fons, M. V.S., Fierro, J. A. M., \& Gómez, M.(2011). Rural tourism: A sustainable alternative,
88, 551-557. https://doi.org/10.1016/j. apenergy.2010.08.031

Ghorbani, A., Rau, V., Ra, P., \& Azadi, H. (2015). Ecotourism sustainable development strategies using SWOT and QSPM model : A case study of Kaji Namakzar Wetland, South Khorasan, 16, 290-297. https:/ /doi. org/10.1016/j.tmp.2015.09.005

Gro, P., \& Stirn, L. Z. (2015). The environmental management problem of Pohorje,Slovenia : A new group approach within ANP e SWOT framework, 161, 106-112. https:// doi.org/10.1016/j.jenvman.2015.06.038

Hassan, S. S. (2000). Determinants of market competitiveness in an environmentally sustainable tourism industry. Journal of Travel Research, 38, 239-245.

Ho, W. (2008). Integrated analytic hierarchy process and its applications - A literature review, 186, 211-228. https://doi. org/10.1016/j.ejor.2007.01.004

Inskeep, E. (1991). Tourism planning: An integrated and sustainable development approach. New York: Van Nostrand Reinhold.

Kajanus, M., Kangas, J., \& Kurttila, M. (2004). The use of value focused thinking and the A ' WOT hybrid method in tourism management, 25, 499-506. https://doi. org/10.1016/S0261-5177(03)00120-1

Kajanus, M., Leskinen, P., Kurttila, M., \& Kangas, J. (2012). Forest Policy and Economics Making use of MCDS methods in SWOT analysis - Lessons learnt in strategic natural resources management. Forest Policy and Economics, 20, 1-9. https://doi. org/10.1016/j.forpol.2012.03.005

Khadaroo, J. \& Seetanah, B. (2008). The role of transport infrastructure in international tourism development: A gravity model approach. Tourism Management, 29, 831840. 
Lin, L. Z. \& Yeh, H. R. (2013). Analysis of tour values to develop enablers using an imperative hierarchy-based model in Taiwan. Tourism Management, 34, 133-144.

Liu, A. (2006). Tourism in rural areas: Kedah, Malaysia. Tourism Management, 27, 878889.

Osman, Z. \& Sentosa, I (2013). Mediating effect of customer satisfaction on service quality and customer loyalty relationship in Malaysian rural tourism. International Journal of Economics and Management Studies, 2(1), 2537.

Rahmani, S. M., Hajari, B., Karimian, T., \& Hakilo, M. (2013). Rural tourism development strategies using SWOT analysis. Life Science Journal, 10(4s), 395-403.

Songan, P., \& Nair, V. (2014). Rural tourism destination competitiveness: A study on Annah Rais Longhouse Homestay, Sarawak. Procedia - Social and Behavioral Sciences, 144, 35-44. https://doi. org/10.1016/j.sbspro.2014.07.271

White, T. H., Melo, Y. De, Develey, P. F., Llerandi-román, I. C., Monsegur-rivera, O. A., \& Trujillo-pinto, A. M. (2015).
Improving reintroduction planning and implementation through quantitative SWOT analysis, 28, 149-159.

Widiyanto, Dodi., Joni Purwohandoyo. Alia Fajarwati. (2008). Pengembangan Pariwisata Perdesaan : Suatu Usulan Strategi Bagi Desa Wisata Ketingan. Jurnal Bumi Lestari, Vol. 8. No. 2. Hal. 205-210.

Wilde, S. J. \& Cox, C. (2008). Linking destination competitiveness and destination development: Findings from a mature Australian tourism destination. Proceedings of the Travel and Tourism Research Association (TTRA) European Chapter Conference - Competition in Tourism: Business and Destination Perspectives, Helsinki, Finland, 467-478.

Yavuz, F., \& Baycan, T. (2013). Use of swot and analytic hierarchy process integration as a participatory decision making tool in watershed management. Procedia Technology, 8(Haicta), 134-143. https: / /doi. org/10.1016/j.protcy.2013.11.019

Zhang, X. (2012). Energy Procedia Research on the Development Strategies of Rural Tourism in Suzhou Based on SWOT Analysis, 16, 12951299. https://doi.org/10.1016/j.eg 